\title{
SIKARTUN: Sistem Informasi Karang Taruna Berbasis Web Menggunakan Metode FDD dan XP
}

\author{
SIKARTUN: Web-Based Karang Taruna Information System Using FDD and XP \\ Method
}

\author{
Navita Putri Purwanti ${ }^{1}$, Septi Andryana ${ }^{2}$, Aris Gunaryati ${ }^{3}$ \\ ${ }^{1}$ Program Studi Sistem Informasi, Universitas Nasional \\ 2,3Program Studi Informatika, Universitas Nasional \\ E-mail: ${ }^{1}$ navitaputrip@gmail.com, ${ }^{2}$ septi.andryana@civitas.unas.ac.id, \\ 3aris.gunaryati@civitas.unas.ac.id
}

\begin{abstract}
Abstrak
Karang Taruna menjadi topik pilihan pada penelitian ini terkait dengan peran pentingnya sebagai wadah kegiatan dan pengembangan generasi muda. Salah satu elemen penting dari organisasi ini adalah informasi dan komunikasi. Umumnya organisasi ini belum memiliki sarana informasi digital seperti website dan hanya menggunakan sarana informasi dari mulut ke mulut. Hal ini mengakibatkan keterlambatan, duplikasi dan ketidakakuratan dalam penyampaian informasi. Objek penelitian ini adalah Karang Taruna RT 005 RW 009 Kelurahan Pondok Labu, Kecamatan Cilandak, Jakarta Selatan. Penelitian ini menerapkan metode gabungan FDD (Feature Driven Development) dan XP (Extreme Programming) dalam pengembangan website SIKARTUN atau Sistem Informasi Karang Taruna agar mempermudah penyampaian informasi tersebut. Desain aplikasi website menggunakan framework CodeIgniter dan Bootsrap, serta bahasa dan database yang digunakan adalah PHP dan MySQL. Hasil penelitian ini, SIKARTUN memiliki kinerja yang baik berdasarkan oleh pengujian Google Lighthouse dan Usabilitiy.
\end{abstract}

Kata kunci: Karang Taruna, Sistem Informasi, Feature Driven Development, XP (Extreme Programming)

\begin{abstract}
Karang Taruna became the topic of choice in this study related to its important role as a forum for activities and development of the younger generation. One of the important elements of this organization is information and communication. Generally, these organizations do not have digital information facilities such as websites and only use word of mouth information. This results in delays, duplication and inaccuracies in the delivery of information. The object of this research is Karang Taruna RT 005 RW 009 Pondok Labu Village, Cilandak District, South Jakarta. This study applies a combined method of FDD (Feature Driven Development) and XP (Extreme Programming) in the development of the SIKARTUN website or Karang Taruna Information System in order to facilitate the delivery of this information. The website application design uses the CodeIgniter and Bootstrap frameworks, and the language and database used are PHP and MySQL. The results of this study, SIKARTUN has a good performance based on Google Lighthouse and Usability testing.
\end{abstract}

Keywords: Youth Organization, Information Systems, Feature Driven Development, XP (Extreme Programming)

\section{PENDAHULUAN}

Karang Taruna ialah sebuah organisasi sosial bersifat formal yang berguna untuk tempat pengembangan jiwa sosial keremajaan. Sebagai organisasi pemuda yang sarat dengan kegiatan, informasi dan komunikasi merupakan dua hal yang paling penting sebagai penunjang kelangsungan organisasi ini. Umumnya organisasi ini belum memiliki sarana informasi digital 
seperti website dan hanya menggunakan sarana informasi dari mulut ke mulut. Hal ini mengakibatkan keterlambatan, duplikasi dan ketidakakuratan dalam penyampaian informasi. Pada saat ini, kondisi objek penelitian di Karang Taruna RT 005 RW 009 Kelurahan Pondok Labu, Kecamatan Cilandak, Jakarta Selatan belum memiliki website sebagai sarana informasi. Sarana yang digunakan sebelumnya melalui chatting dan mulut ke mulut. Hal ini mengakibatkan keterlambatan dan memerlukan waktu cukup lama dalam proses penyampaian informasi kepada warga terkait hal penting pada Karang Taruna. Selain itu, setiap kegiatan yang diselenggarakan oleh Karang Taruna tidak terkelola dengan baik sebagai mana mestinya, diantaranya dicatat di buku maupun note di HP. Masalah terakhir, tidak adanya wadah dokumentasi, setiap foto atau bukti yang dilakukan oleh Karang Taruna tersimpan di HP orangorang tertentu yang ini tidak dapat di lihat oleh yang lainnya. Maka, dibutuhkan sebuah sistem informasi agar masalah dapat teratasi. Memberikan informasi akurat dan relevan mengenai Karang Taruna adalah cara terbaik untuk menjaga sosialisasi agar tetap terjalin[1].

Pada penelitian ini terdapat beberapa referensi yang terkait dengan topik. Jurnal pertama dengan metode waterfall pemodelan UML (Unified Modeling Language) membantu menyelesaikan tahapan secara berurutan, sehingga proses rancangan lebih teliti. Kekurangan terdapat pada metode waterfall yaitu menjadi tidak fleksibel apabila ada revisi pada sistem yang dibangun[2]. Jurnal kedua membuat website pengelolaan Karang Taruna dengan metode pengumpulan data observasi, wawancara dan studi pustaka telah sesuai harapan dengan hasil yang divalidasi guna memudahkan user dalam menggunakan website. Kekurangan terdapat pada pengujian black box yang dapat memungkinkan pengulangan tes yang telah dilakukan[3]. Jurnal ketiga menggunakan bahasa pemrograman PHP dan database MySQL dengan hasil bisa digunakan pada computer secara online karena lebih efektif. Kekurangan terdapat pada gambar yang disajikan tidak terlihat jelas[4]. Jurnal keempat menggunakan metode XP (Extreme Programming) dan framework Bootstrap bisa mengatasi masalah yang ada dengan lebih efektif dan efisien. Kekurangan terdapat pada penulisan jurnal yang ejaannya kurang benar[5]. Selain itu, penelitian ini juga terdapat pembanding website yaitu pada website Karang Taruna Sardonoharjo dan website Karang Taruna Kabupaten Pati yang hanya terdapat sedikit fitur. Dari referensi tersebut terkhusus dari kekurangan yang telah dijelaskan, maka pada penelitian ini menggunakan metode gabungan yaitu metode FDD (Feature Driven Development) dan metode XP (Extreme Programming) guna menghasilkan kualitas sistem yang mudah dipahami, fitur lebih lengkap dan cepat dalam pembuatan sistem serta mengusulkan menu tambahan dan tampilan web yang berbeda dari website pembanding untuk Sistem Informasi Karang Taruna yang akan dibuat guna memudahkan user dalam mengakses web dan metode testing dengan menggunakan Google Lighthouse serta Usability.

Penelitian ini bertujuan untuk membuat atau membangun sistem informasi berbasis web berdasarkan fakta atau masalah yang terjadi pada Karang Taruna RT 005 RW 009 Kelurahan Pondok Labu, Kecamatan Cilandak, Jakarta Selatan dengan dinamakan (SIKARTUN) atau Sistem Informasi Karang Taruna agar efisien. Sistem Informasi ini berfungsi sebagai wadah informasi, diantaranya yang dapat mengolah data ialah admin (kepengurusan Karang Taruna), sebagai tempat dokumentasi kegiatan berupa foto, fitur berita untuk informasi seputar kegiatan, tabel berkas sebagai wadah surat-surat yang dapat dilihat user, kalender untuk pengingat kegiatan yang akan diselenggarakan. User dapat melihat informasi melalui web, mendownload file berkas dan kontak yang terhubung dengan WhatsApp guna komunikasi. Dalam merancang sistem informasi ini, pertama peneliti menggunakan metode FDD (Feature Driven Development) dari tahap build an overall model hingga design by feature agar sistem yang dibangun dapat mudah dipahami dan dapat diperiksa secara efektif, selanjutnya menggunakan metode XP (Extreme Programming) pada coding dan testing guna menghasilkan peningkatan kualitas dari sistem menjadi fleksibel. Dengan sistem ini dapat memudahkan warga mencari informasi.

Penelitian ini terdapat beberapa studi literatur yang diantaranya yaitu Sistem Informasi menurut Kadir (2014) adalah sistem informasi menggunakan komputer atau sama dengan Sistem Informasi Berbasis Komputer[4]. Karang Taruna adalah organisasi kepemudaan sebagai 
wadah pengembangan jiwa sosial remaja yang tumbuh atas rasa kesadaran dan tanggung jawab sosial[4]. Metode FDD (Feature Driven Development) ialah metode pendekatan agile yang mengacu kepada pembuatan sistem agar mudah dipahami, diimplementasi, teknik problem solving dan juga pelaporan yang dapat dikontrol oleh stakeholders[6]. Metode Extreme Programming (XP) ialah metode pengembangan software untuk meningkatkan kualitas pada software[5]. Codeigniter merupakan framework PHP yang bertujuan untuk mempercepat pengembangan aplikasi web yang dilakukan oleh developer[7].

\section{METODE PENELITIAN}

\subsection{Metode FDD (Feature Driven Development)}

Metode pertama yang dilakukan oleh peneliti adalah metode FDD. Metode ini dimulai pada build an overall model hingga design by feature. Metode FDD ialah metode pendekatan agile yang mengacu kepada pembuatan sistem agar mudah dipahami, diimplementasi, teknik problem solving dan juga pelaporan yang dapat dikontrol oleh stakeholders[6]. Karena itu, peneliti memilih metode ini agar sistem yang dibangun dapat mudah dipahami dan dapat diperiksa secara efektif.

Berikut adalah tahapan pada metode FDD yang akan dilakukan oleh peneliti:

1. Build an Overall Model

Pada tahap pertama, mengumpulkan informasi yang akan diteliti dengan cara studi literatur melalui jurnal, observasi dengan mengamati masalah dan wawancara dengan pengurus Karang Taruna.

2. Build a Feature List

Pada tahap kedua, mengidentifikasikan fitur untuk di list sesuai dengan kebutuhan pada sistem yang akan dibangun.

3. Plan by Feature

Pada tahap ketiga, menentukan perencanaan yang akan dibuat supaya berjalan dengan baik sesuai dengan fitur yang dibutuhkan.

4. Design by Feature

Pada tahap keempat, membuat desain use case guna menunjukkan alur kerja sistem.

5. Build by Feature

Pada tahap terakhir, membangun sistem menggunakan bahasa pemrograman PHP, database MySQL, framework CodeIgniter serta Bootsrap dan software text editor Visual Studio Code.

\subsection{Metode XP (Extreme Programming)}

Setelah metode FDD, yang digabungkan pada metode XP yaitu pada Coding dan Testing. Metode XP merupakan metode pengembangan perangkat lunak dengan peningkatan kualitas sistem lebih cepat[5]. Karena itu, peneliti memilih metode ini agar system menjadi fleksibel. Berikut adalah tahapan gambaran metode XP (Extreme Programming):

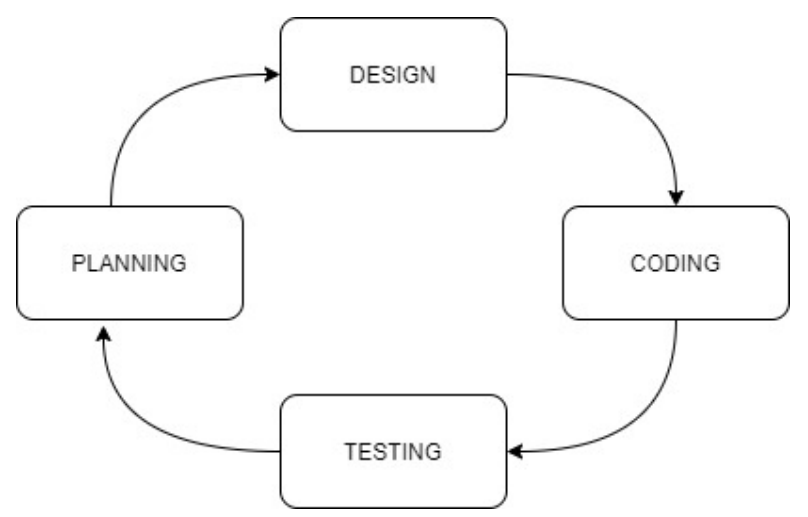

Gambar 2. Tahapan Metode XP 
Berikut ini yaitu tahapan pada metode Extreme Programming (XP):

1. Planning

Tahap ini yaitu perencanaan yang dimulai dengan identifikasi masalah pada penelitian.

2. Design

Tahap ini yaitu membuat pemodelan sistem. Pemodelan yang digunakan ialah use case diagram dan rancangan sistem website.

3. Coding

Tahap ini yaitu penerapan pemodelan sistem menggunakan Bahasa pemrograman PHP dan text editor yaitu Visual Studio Code.

4. Testing

Tahap ini yaitu mengecek apakah sistem terjadi kesalahan atau tidak. Menggunakan tools Google Lighthouse dan Usability.

\subsection{Flowchart Metode Penelitian}

Flowchart Metode Penelitian ini merupakan alur dari metode penelitian yang dibuat[9].

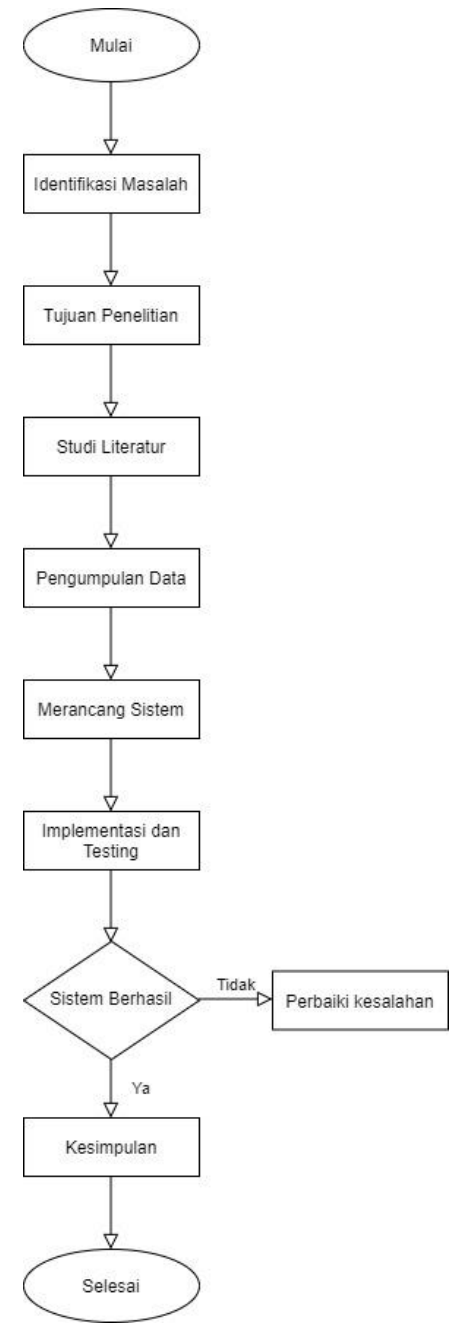

Gambar 3. Flowchart Metode Penelitian

1. Identifikasi Masalah

Identifikasi masalah yaitu menelaah suatu masalah sebelum di rumuskan, ini merupakan hal penting supaya tidak terjadi kesalahan pada langkah selanjutnya. 
2. Tujuan Penelitian

Tujuan penelitian dilakukan peneliti dengan cara Observasi dan Wawancara untuk mengetahui data dan fakta masalah yang akan diteliti pada jurnal.

3. Studi Literatur

Studi literatur yaitu suatu studi atau referensi yang berguna untuk pemahaman yang lebih pada data yang akan diteliti supaya penelitian relevan. Peneliti mencari referensi berupa jurnal yang bereputasi dan terakreditasi.

4. Pengumpulan Data

Pengumpulan data yaitu mengumpulkan data yang telah di dapat sebelum dilakukan perancangan system. Data disesuaikan dengan saat wawancara.

5. Perancangan Sistem

Perancangan SIKARTUN dilakukan oleh peneliti menggunakan bahasa pemrograman PHP, database yaitu MySQL, desain aplikasi dengan framework CodeIgniter dan Bootsrap serta software untuk coding menggunakan Visual Studio Code.

6. Implementasi dan Testing

Implementasi dan testing dilakukan supaya sistem berjalan dengan lancar tanpa ada kesalahan dan sesuai dengan rencana. Dengan mengecek kembali coding, apabila terdapat kesalahan di perbaiki. Jika sudah tidak ada kesalahan lanjut ke tahap berikutnya.

7. Kesimpulan

Terakhir yaitu kesimpulan, ini dilakukan saat sistem sudah berjalan dengan baik atau tidak ada kesalahan.

\subsection{Flowchart Rancangan SIKARTUN}

SIKARTUN merupakan Sistem Informasi Karang Taruna berbasis web pada Karang Taruna RT 005 RW 009 Kelurahan Pondok Labu, Kecamatan Cilandak, Jakarta Selatan yang berguna sebagai wadah informasi seputar kegiatan Karang Taruna. Aplikasi ini dibuat dengan user friendly (mudah digunakan) dan desain web yang responsive[7]. Gambaran flowchart pada rancangan ini sebagai berikut :

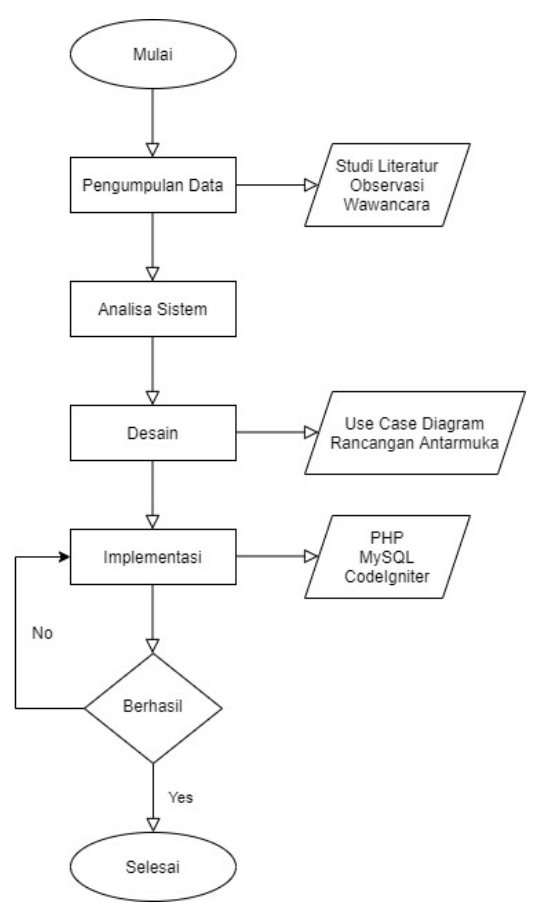

Gambar 4. Flowchart Rancangan SIKARTUN 


\subsection{Desain Rancangan SIKARTUN}

Rancangan antarmuka ini dibuat untuk memenuhi kebutuhan informasi. Fungsi dari Sistem Informasi Karang Taruna (SIKARTUN) yaitu untuk wadah informasi seputar Karang Taruna dan mempermudah dalam penggunaannya melalui website[3]. Berikut adalah gambaran desain sistem:

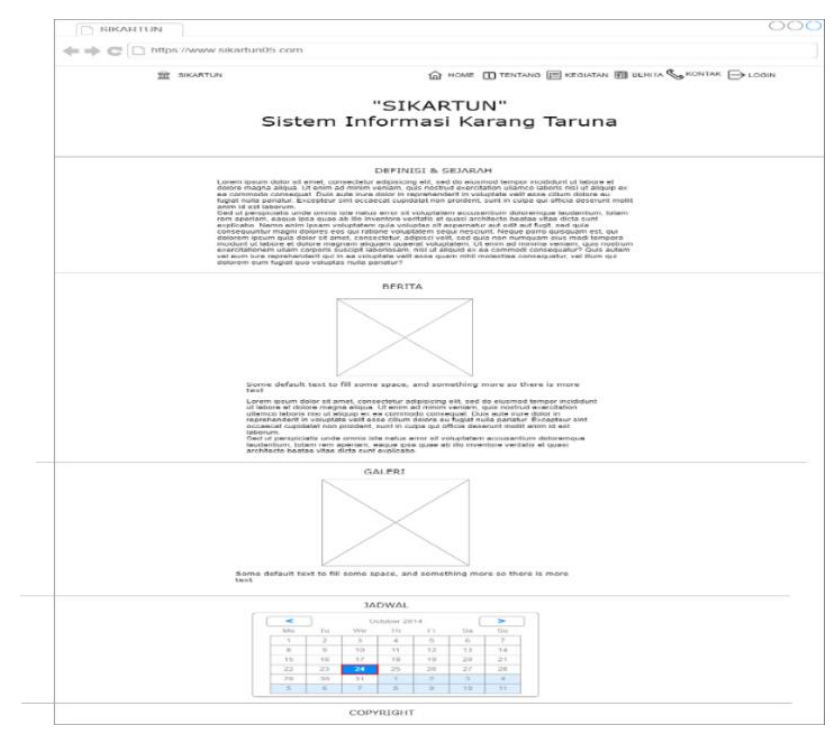

Gambar 5. Desain Rancangan SIKARTUN

\subsection{Use Case Diagram SIKARTUN}

Dalam penelitian ini, peneliti menggunakan pemodelan UML (Unified Modelling Language) yaitu Use Case Diagram untuk SIKARTUN. Pada hal ini, hanya Admin yang dapat login ke web SIKARTUN. Admin login untuk mengolah data yang termasuk di dalamnya seperti mengedit, menambahkan, menghapus data seputar Karang Taruna. Dan User diperuntukan hanya melihat informasi yang ada pada website SIKARTUN[2]. Gambarannya seperti berikut :

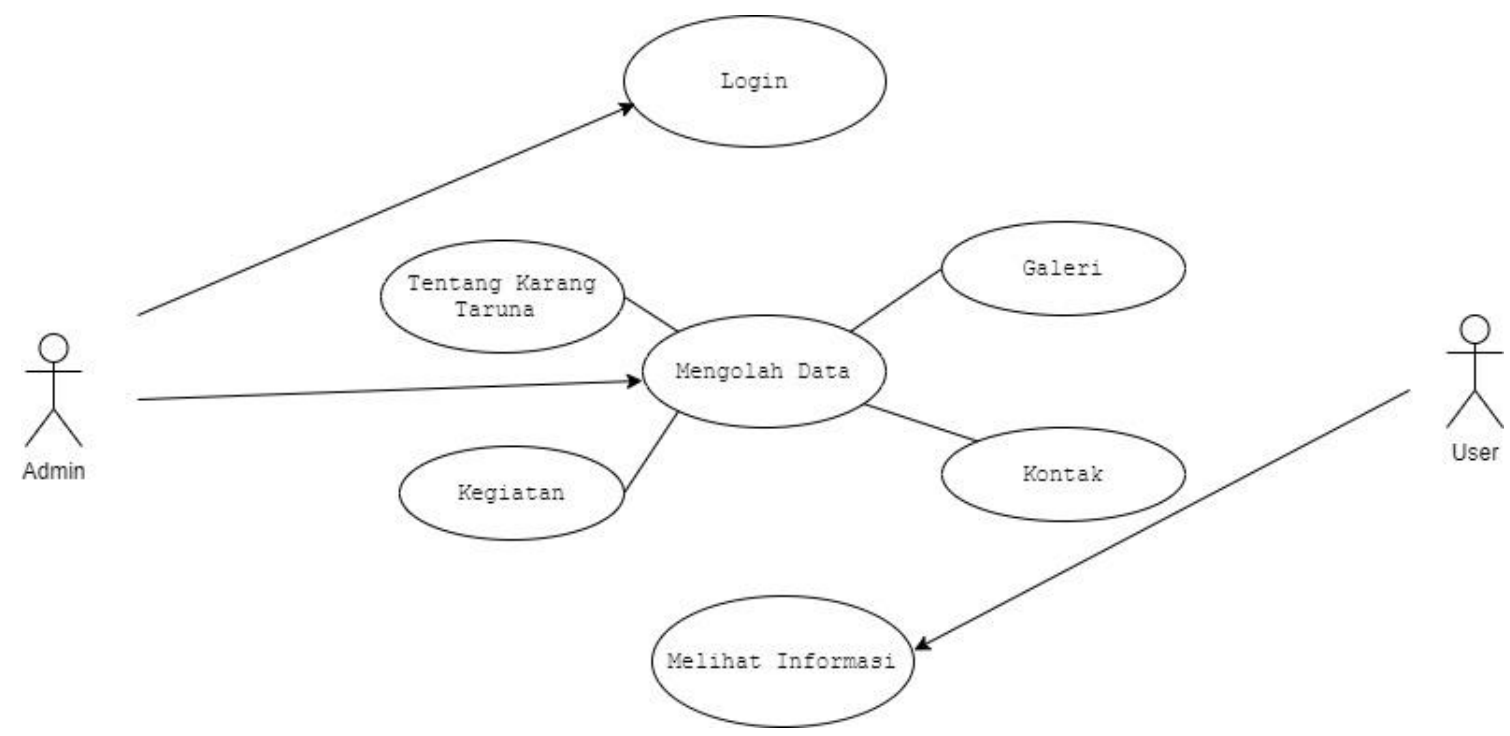

Gambar 6. Use Case Diagram SIKARTUN 


\subsection{Implementasi Sistem}

\section{HASIL DAN PEMBAHASAN}

Implementasi sistem merupakan tahap penerapan sistem yang telah direncanakan dan dirancang. Tujuan implementasi adalah untuk menjelaskan penggunaan sistem kepada user agar merespon apa yang ditampilkan pada sistem sesuai dengan kebutuhan.

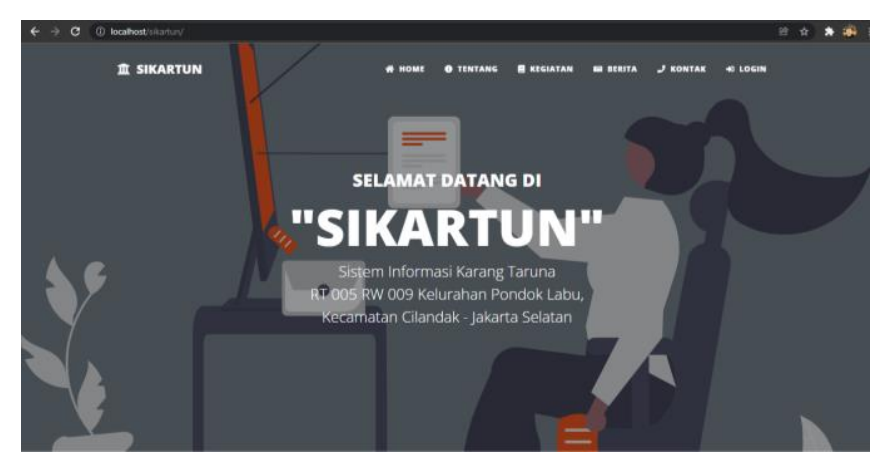

Gambar 7. Tampilan Home SIKARTUN

Website SIKARTUN yang dibuat pada penelitian ini terdiri dari 6 fitur, diantaranya yaitu Home, Tentang, Kegiatan, Berita, Kontak dan Login untuk Admin.

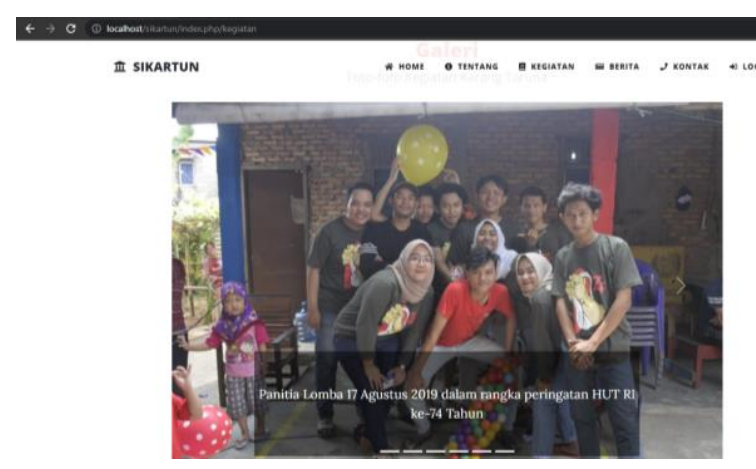

Gambar 8. Tampilan Galeri SIKARTUN

Tampilan Galeri ini untuk bukti kegiatan Karang Taruna berupa foto. Wadah dokumentasi ini dibuat untuk memenuhi kebutuhan website yang telah direncanakan. User dapat melihat galeri pada menu home dan atau kegiatan.

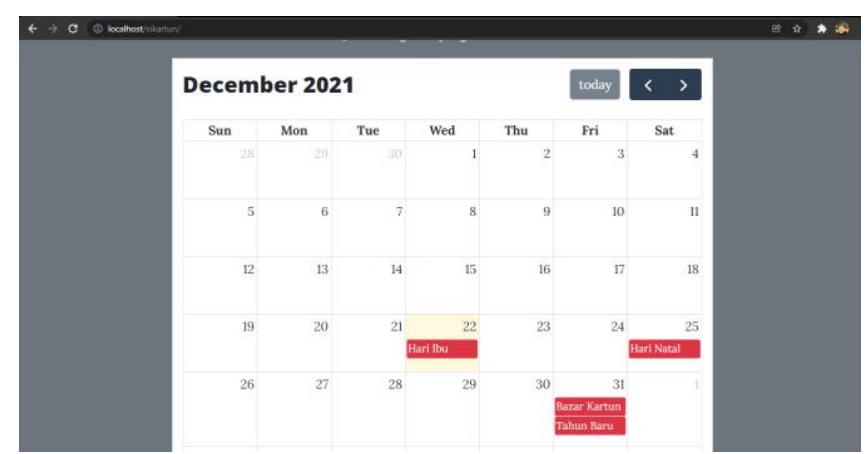

Gambar 9. Tampilan Kalender SIKARTUN

Tampilan Kalender dibuat untuk memenuhi kebutuhan pada perencanaan sebelumnya yang berfungsi untuk pengingat setiap kegiatan yang akan diselenggarakan oleh Karang Taruna. 
User dapat melihat kalender kegiatan pada menu home dan atau kegiatan.

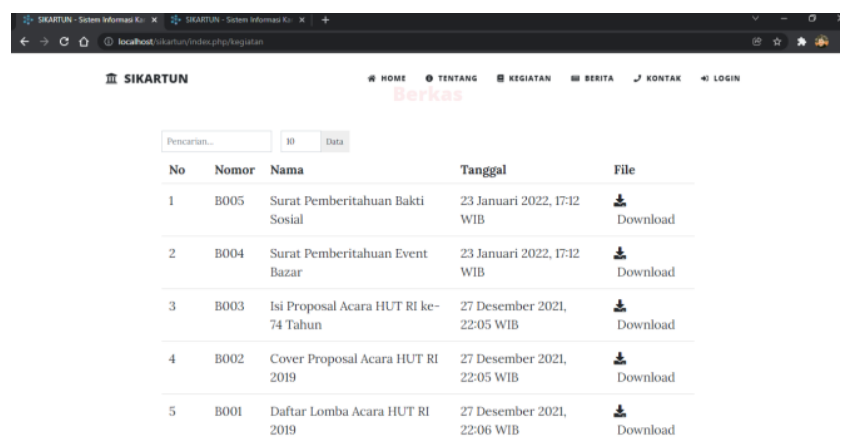

Gambar 10. Tampilan Berkas SIKARTUN

Tampilan Berkas berfungsi untuk tempat berkas-berkas Karang Taruna dalam setiap penyelenggaraan acara yang dapat di download oleh user dan sebagai aspek Sistem Informasi. User dapat melihat serta mendownload file berkas pada menu kegiatan.

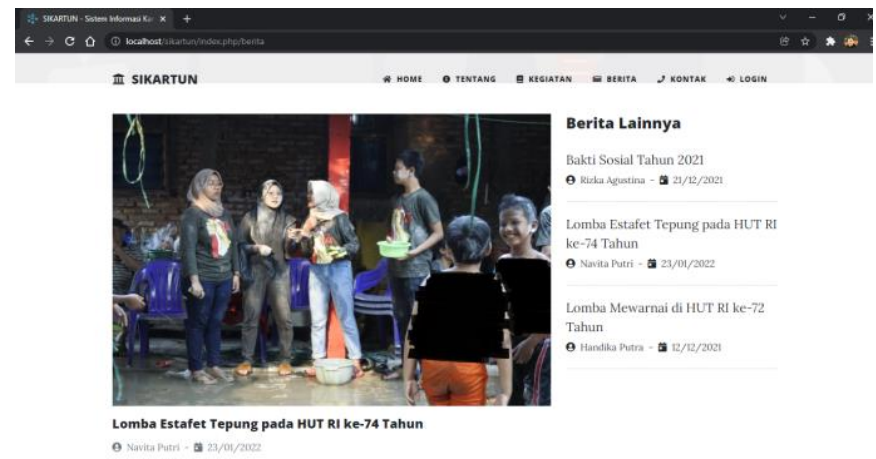

Gambar 11. Tampilan Berita SIKARTUN

Tampilan Berita berfungsi sebagai wadah informasi seputar Karang Taruna yang terbaru dan sebagai aspek Sistem Informasi. User dapat melihat berita pada menu home dan atau berita.

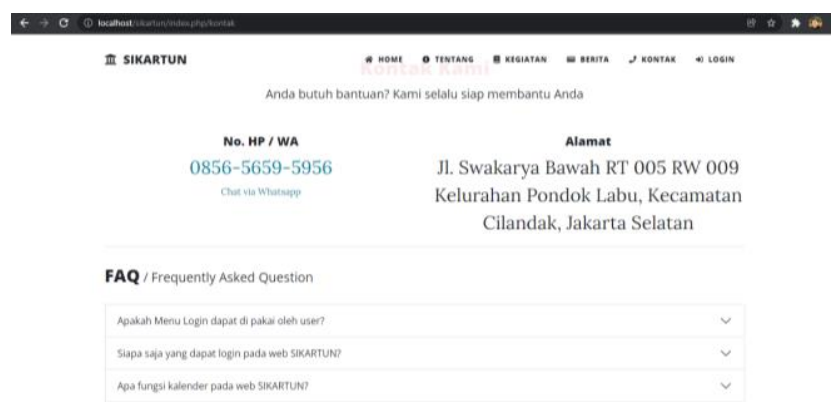

Gambar 12. Tampilan Kontak SIKARTUN

Tampilan Kontak berfungsi sebagai tempat user dapat menghubungi pihak Karang Taruna apabila diperlukan dan terdapat FAQ untuk pertanyaan pada user dan juga sebagai aspek Sistem Informasi. User dapat melihat kontak pada menu kontak. 


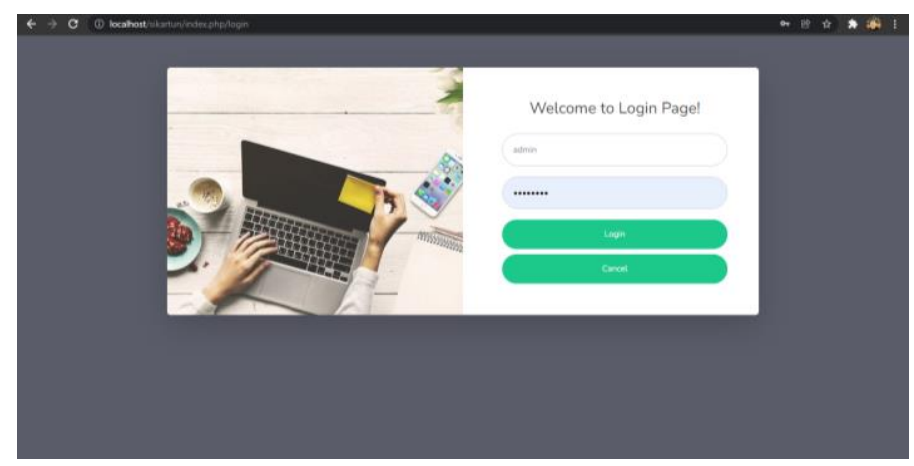

Gambar 13. Tampilan Halaman Login Admin

Tampilan halaman login untuk admin yang mengolah data pada website SIKARTUN.

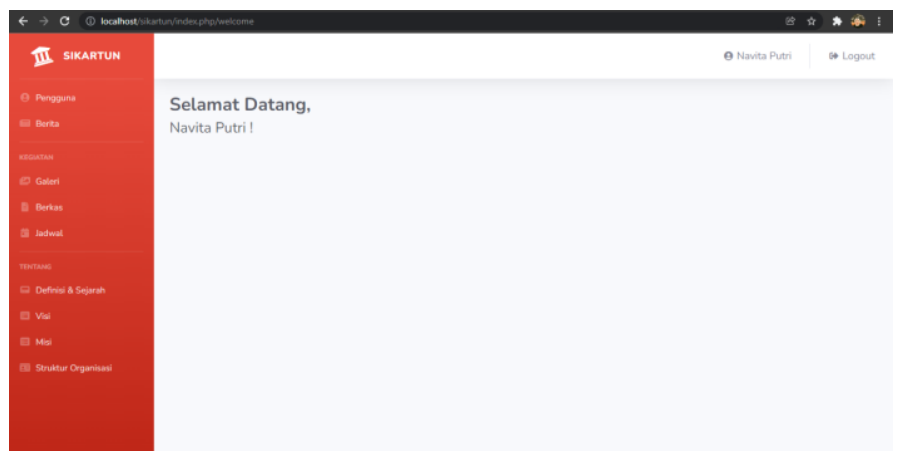

Gambar 14. Tampilan Dashboard Admin

Tampilan dashboard admin untuk mengolah data, berupa Admin multi-user, Berita, Galeri, Berkas, Jadwal (Kalender), Definisi dan Sejarah, Visi, Misi dan Struktur Organisasi.

\subsection{Pengujian tools Google Lighthouse}

Pengujian atau testing pada sistem dimaksudkan untuk mengecek sistem yang dibuat sudah berjalan dengan lancar atau belum dan sesuai dengan kebutuhan. Pengujian sistem pada penelitian ini menggunakan Google Lighthouse yang berguna untuk menguji kinerja atau kualitas sistem[10]. Parameter yang diuji diantaranya Performance yaitu menilai kinerja web, Accessibility yaitu memeriksa masalah yang umum terjadi, Best Practices yaitu memeriksa kode situs web yang dibuat sudah berjalan baik atau belum dan SEO yaitu memeriksa web dalam melakukan praktik apakah mudah ditemukan pada mesin pencarian. Hasil parameter yang diuji diukur dengan skor penilaian sesuai yang ada pada Google Lighthouse. Berikut adalah tabel skor penilaian dan hasil pengujiannya:

Tabel 1 Skor Penilaian SIKARTUN

\begin{tabular}{|c|c|c|}
\hline Status & Skor & Warna Status \\
\hline Kurang Baik & $0-49$ & \\
\hline Cukup Baik & $50-89$ & \\
\hline Sangat Baik & $90-100$ & \\
\hline
\end{tabular}

Tabel 2 Pengujian SIKARTUN pada Google Lighthouse

\begin{tabular}{|c|c|c|c|c|c|}
\hline No & Menu SIKARTUN & Performance & Accessibility & Best Practices & SEO \\
\hline 1 & Home & 97 & 86 & 93 & 70 \\
\hline 2 & Tentang & 98 & 89 & 93 & 80 \\
\hline 3 & Kegiatan & 93 & 90 & 93 & 70 \\
\hline 4 & Berita & 96 & 88 & 93 & 80 \\
\hline 5 & Kontak & 99 & 98 & 93 & 89 \\
\hline 6 & Login Admin & 99 & 97 & 87 & 89 \\
\hline
\end{tabular}


Keterangan dari tabel 3.2 yaitu pengujian telah sukses dilakukan yang berarti kinerja atau kualitas SIKARTUN yang dibuat dikategorikan baik dengan rata-rata Performance 97, Accessibility 91.3, Best Practice 92 dan SEO 79.67 maka dapat digunakan oleh user.

\title{
3.3 Usability Testing SIKARTUN
}

Pengujian ini dimaksudkan untuk mengecek sistem sudah sesuai dengan kebutuhan atau belum melalui tiga komponen diantaranya kecepatan load pada web, mendownload file pada berkas dan terhubung pada WhatsApp dan terdapat pertanyaan untuk website lain sebagai pembanding SIKARTUN serta jumlah user yang diuji 20 orang dan 10 pertanyaan melalui kuesioner[11]. Interaksi website dengan user pada berkas yang dapat didownload dan menu Kontak, user dapat mengklik nomor WhatsApp untuk terhubung. Skala untuk hasil testing dengan skor 5-7 berarti dikategorikan telah sesuai dan efisien. Hasil didapat sistem bekerja dengan baik atau telah sesuai serta efisien berdasar jumlah nilai rata-rata dan skor skala. Berikut adalah tabel skala penilaian dan hasil dari testing sistem kepada user:

Tabel 3 Skala Penilaian Usability SIKARTUN

\begin{tabular}{|c|c|}
\hline Keterangan & Skor \\
\hline Kurang Baik / Sesuai & $1-3$ \\
\hline Cukup Baik / Sesuai & 4 \\
\hline Sangat Baik / Sesuai & $5-7$ \\
\hline
\end{tabular}

\author{
Rumus Nilai Rata-rata \\ Skor: Jumlah Responden x Persentase \\ Isi Tabel Skor $=$ Jumlah Responden
}

Tabel 4 Usability Testing SIKARTUN

\begin{tabular}{|c|c|c|c|c|c|}
\hline No & Pertanyaan & Skor 1-3 & Skor 4 & Skor 5-7 & Nilai Rata-rata \\
\hline 1 & $\begin{array}{l}\text { Bagaimana kecepatan loading pada } \\
\text { website SIKARTUN? }\end{array}$ & & 2 & 18 & 6,55 \\
\hline 2 & $\begin{array}{l}\text { Apakah file berkas pada menu Kegiatan di } \\
\text { website SIKARTUN dapat di download? }\end{array}$ & & 2 & 18 & 5,85 \\
\hline 3 & $\begin{array}{l}\text { Apakah Anda dapat terhubung ke } \\
\text { WhatsApp pada menu Kontak } \\
\text { SIKARTUN? }\end{array}$ & & 1 & 19 & 6,55 \\
\hline 4 & $\begin{array}{l}\text { Apakah website SIKARTUN menarik } \\
\text { dilihat daripada website pembanding? }\end{array}$ & 1 & 1 & 18 & 6,55 \\
\hline 5 & $\begin{array}{l}\text { Apakah tampilan website SIKARTUN } \\
\text { mudah dikenali daripada website } \\
\text { pembanding? }\end{array}$ & & 2 & 18 & 6,6 \\
\hline 6 & $\begin{array}{l}\text { Apakah menu dan isi dari website } \\
\text { SIKARTUN lebih lengkap daripada } \\
\text { website pembanding? }\end{array}$ & & 1 & 19 & 4,75 \\
\hline 7 & $\begin{array}{l}\text { Apakah Anda puas dengan informasi yang } \\
\text { disajikan pada website SIKARTUN? }\end{array}$ & 1 & 1 & 18 & 5,9 \\
\hline 8 & $\begin{array}{l}\text { Apakah fitur yang terdapat pada } \\
\text { SIKARTUN sesuai dengan fungsinya? }\end{array}$ & & 1 & 19 & 8,15 \\
\hline 9 & $\begin{array}{l}\text { Menurut Anda, apakah website } \\
\text { SIKARTUN mudah digunakan? }\end{array}$ & & 2 & 18 & 8,2 \\
\hline 10 & $\begin{array}{l}\text { Menurut Anda, Apakah website } \\
\text { SIKARTUN telah efisien sebagai wadah } \\
\text { informasi? }\end{array}$ & & 1 & 19 & 7,3 \\
\hline & Jumlah Nilai Rata-rata & \multicolumn{4}{|c|}{ 66,4 } \\
\hline \multicolumn{2}{|r|}{ Jumlah Nilai Rata-rata / Jumlah Pertanyaan } & \multicolumn{4}{|c|}{6,64} \\
\hline \multicolumn{2}{|c|}{ Pembulatan / Skala } & \multicolumn{4}{|c|}{7} \\
\hline
\end{tabular}

\section{KESIMPULAN DAN SARAN}

Berdasarkan apa yang sudah dijelaskan pada penelitian ini, maka kesimpulan yaitu sudah sesuai dengan harapan bahwa dibutuhkan sistem informasi yang berguna untuk penyampaian informasi terkait organisasi Karang Taruna memiliki hasil kinerja website sukses dan baik berdasar pengujian pada Google Lighthouse dan Usability. Sistem informasi ini dapat digunakan oleh user untuk melihat informasi, mendownload file berkas, kontak yang terhubung dengan WhatsApp dan admin website untuk mengolah data di mana admin merupakan anggota 
kepengurusan Karang Taruna. Kelebihan pada penelitian ini adalah sistem informasi yang dibuat user friendly (mudah digunakan) dengan web yang responsive dan terdapat fitur lebih lengkap dari website yang menjadi pembanding. Disamping adanya kelebihan juga ada kekurangan, diharapkan pada penelitian selanjutnya sistem dapat dikembangkan oleh developer dengan lebih baik dan peneliti menyarankan menambahkan fitur arsip dokumentasi pada setiap bidang kepengurusan dan fitur e-voting untuk pemilihan pengurus Karang Taruna.

\section{DAFTAR PUSTAKA}

[1] H. Almaimoni et al., "Developing and Implementing WEB-based Online Destination Information Management System for Tourism," International Journal of Applied Engineering Research, vol. 13, no. 10, pp. 7541-7550, 2018, [Online]. Available: http://www.ripublication.com

[2] F. Akbar and S. Setiaji, "RANCANG BANGUN SISTEM INFORMASI KARANG TARUNA MENGGUNAKAN METODE WATERFALL," JURNAL KHATULISTIWA INFORMATIKA, vol. VIII, no. 1, 2020, [Online]. Available: www.bsi.ac.id

[3] Pamungkas Regen $\mathrm{T}$ and Tofan Rapiyanta P, "Sistem Informasi Pengelolaan Kegiatan Karang Taruna (SIPEKATAR) Naralatu Agantuka Berbasis Website," Prosiding Nasional Rekayasa Teknologi Industri dan Informatika, pp. 324-331, 2019.

[4] I. Nur Amanda, A. Hafiz Ramadani, and C. Responden, "RANCANG BANGUN SISTEM INFORMASI MEDIA KEGIATAN PADA LEMBAGA KARANG TARUNA KECAMATAN SEPATAN TIMUR," JIKA (Jurnal Informatika), pp. 104-108, 2021.

[5] H. Ismatullah and Q. Jafar Adrian, "IMPLEMENTASI PROTOTYPE DALAM PERANCANGAN SISTEM INFORMASI IKATAN KELUARGA ALUMNI SANTRI BERBASIS WEB," Jurnal Informatika dan Rekayasa Perangkat Lunak (JATIKA), vol. 2 , no. 2, pp. 213-220, 2021, [Online]. Available: http://jim.teknokrat.ac.id/index.php/informatika

[6] A. Rifai and Y. Prabawati Yuniar, "Penerapan Metode Waterfall Dalam Perancangan Sistem Informasi Ujian Pada SMK Indonesia Global Berbasis Web," JURNAL KHATULISTIWA INFORMATIKA, vol. VII, no. 1, 2019.

[7] N. Cahya, A. Triayudi, and B. Benrahman, "Implementasi Framework Codeigniter Pada Perancangan Chatbot Interaktif Menerapkan Metode Waterfall," JURNAL MEDIA INFORMATIKA BUDIDARMA, vol. 5, no. 1, pp. 273-279, Jan. 2021, doi: 10.30865/mib.v5i1.2623.

[8] Putri R M, Renaldi F, and Santikarama I, "Pembangunan Sistem Informasi Monitoring Pengelolaan Kegiatan Karang Taruna Kecamatan Padalarang," Seminar Nasional Aplikasi Teknologi Informasi (SNATi), 2019.

[9] R. Firmansyah, S. Andryana, and B. Benrahman, "Sistem Informasi Laporan Asset Fakultas Teknologi Komunikasi dan Informatika Universitas Nasional," JURNAL MEDIA INFORMATIKA BUDIDARMA, vol. 4, no. 3, pp. 574-581, Jul. 2020, doi: 10.30865/mib.v4i3.2150.

[10] P. H. Pangestu, R. Tulloh, and R. Adiati, "PERANCANGAN DAN IMPLEMENTASI APLIKASI PELAYANAN KESEHATAN PUSKESMAS BERBASIS WEB MENGGUNAKAN FRAMEWORK LARAVEL (STUDI KASUS PUSKESMAS MULYAHARJA) Design and Implementation of Web Based Publlic Health Center Application Using Laravel Framework (Case Study Of Mulyaharja Publlic Health Center)," e-Proceeding of Applied Science, vol. 7, no. 5, pp. 1818-1835, 2021.

[11] S. Kasus et al., "EVALUASI USABILITY TERHADAP SISTEM PROMOSI PARIWISATA BERBASIS ANDROID DAN WEB (Studi Kasus: Objek Pariwisata di Provinsi Bengkulu)," Jurnal Rekursif, vol. 7, no. 2, 2019, [Online]. Available: http://ejournal.unib.ac.id/index.php/rekursif/ 